\title{
NLRP3 inflammasome activation in murine macrophages caused by Neospora caninum infection
}

Xiaocen Wang ${ }^{\dagger}$, Pengtao Gong ${ }^{\dagger}$, Xu Zhang, Jielin Wang, Lixin Tai, Xu Wang, Zhengkai Wei, Yongjun Yang, Zhengtao Yang, Jianhua Li ${ }^{*}$ and Xichen Zhang ${ }^{*}$

\begin{abstract}
Background: Neospora caninum is an intracellular parasite that causes significant economic losses in cattle industry. Understanding the host resistance mechanisms in the innate immune response to neosporosis could facilitate the exploration of approaches for controlling N. caninum infection. The NLR inflammasome is a multiprotein platform in the cell cytoplasm and plays critical roles in the host response against microbes.

Methods: Neospora caninum-infected wild-type (WT) macrophages and N/rp3 ${ }^{-/-}$macrophages, and inhibitory approaches were used to investigate inflammasome activation and its role in N. caninum infection. Inflammasome RT Profiler PCR Arrays were used to identify the primary genes involved in $N$. caninum infection. The expression of the sensor protein NLRP3, processing of caspase-1, secretion of IL-1 $\beta$ and cell death were detected. Neospora caninum replication in macrophages was also assessed.

Results: Many NLR molecules participated in the recognition of N. caninum, especially the sensor protein NLRP3, and further study revealed that the NLRP3 distribution became punctate in the cell cytoplasm, which facilitated inflammasome activation. Inflammasome activation-mediated caspase-1 processing and IL-1 $\beta$ cleavage in response to $\mathrm{N}$. caninum infection were observed and were correlated with the time of infection and number of infecting parasites. LDH-related cell death was also observed, and this death was regarded as beneficial for the clearance of N. caninum. Treatment of N. caninum-infected macrophages with caspase-1, pan-caspase and NLRP3 inhibitors led to the impaired release of active IL-1 $\beta$ and a failure to restrict parasite replication. And Neospora caninum infected peritoneal macrophages from N/rp3-deficient mice displayed greatly decreased release of active IL-1 $\beta$ and the failure of caspase-1 cleavage.
\end{abstract}

Conclusions: The NLRP3 inflammasome can be activated in N. caninum-infected macrophages, and plays a protective role in the host response to control N. caninum.

Keywords: Neospora caninum, Macrophages, NLRP3 inflammasome, Caspase-1, IL-1 $\beta$

\section{Background}

Neospora caninum is a protozoan parasite with a wide host range. It mainly causes a serious disease in cattle and dogs worldwide [1]. Neosporosis, which leads to significant economic losses in both the dairy and beef industries around the world, is a major cause of abortions in the cattle industry, and has been associated with

\footnotetext{
* Correspondence: jianhuali7207@163.com; xczhang@jlu.edu.cn

${ }^{\dagger}$ Equal contributors

College of Veterinary Medicine, Jilin University, Jilin, Changchun 130062, China
}

neonatal mortality and neurological clinical signs in congenitally infected calves [2-4]. Although similar in life-cycle, subcellular ultrastructure, invasion mechanism, metabolic pathway and genome organization, $N$. caninum differs from Toxoplasma gondii in host range, virulence factors and disease pathogenesis [5]. Analyses of the genome of Neospora and the transcriptomes of both Neospora and Toxoplasma have shown that there are many differences in the groups of genes that interact with the host, and these differences may lead to changes in interactions with the host immune mechanisms [6]. 
Therefore, a good understanding of the immune mechanisms that mediate host resistance to neosporosis may facilitate the discovery of approaches to control neosporosis.

As it is an intracellular parasite, the intracellular proliferation of $N$. caninum tachyzoites is a key step in the pathogenesis of neosporosis. The innate immune system is the first line of defense in host resistance to N. caninum infection, playing an important role in the control of the initial parasite replication and then mediating an appropriate adaptive immune response [7]. Pattern recognition receptors (PRRs) of innate immune cells, such as macrophages, can sense microbes by recognizing the pathogen-associated molecular patterns (PAMPs) of pathogens [8]. Studies show that TLR2 [9] and TLR3 [5], which belong to the Toll-like receptors (TLRs) family, participate in the initial recognition of $N$. caninum, induce the secretion of the pro-inflammatory cytokines IL-12 and IFN- $\gamma$, and mediate the immune response against $N$. caninum.

In recent years, studies have reported that another group of PRRs, termed nucleotide oligomerization domain (Nod)-like receptors (NLRs), plays important roles in the host response to the pathogenesis of infections caused by intracellular parasites [10]. NLRs are intracellular cytosolic sensors and are defined by a tripartite structure [11]. They can be divided to two groups. One group mediates NF- $\mathrm{kB}$ activation via NOD1 and NOD2 [12], and a recent $N$. caninum study shows that the murine NOD2-mediated response contributes to $N$. caninum elimination and the pathogenesis of neosporosis [7]. Another group of NLRs can sense multiplying PAMPs or danger-associated molecular patterns (DAMPs) and induce the assembly of the inflammasome, a multiprotein platform in the cell cytoplasm, to initiate the host defense against infectious pathogens [13]. The NLRP3 inflammasome senses various molecules, such as extracellular ATP, nigericin and uric acid crystals [14], and numerous bacteria, viruses, fungi and parasites [11]. Activation of the murine NLRP3 inflammasome requires two signals in macrophages. The first signal is typically provided by the activation of NF- $\mathrm{KB}$ (after LPS treatment, for example) and induces the transcriptional upregulation of NLRP3 and pro- IL-1 $\beta /$ pro- IL-18; the second signal is provided by the above stimuli and then causes inflammasome complex formation, and caspase- 1 is engaged to proteolytically cleave pro-IL $1 \beta /$ pro-IL- 18 into active IL-1 $\beta / \mathrm{IL}-18$ [11]. Meanwhile, active caspase-1 also triggers a form of programmed cell death known as pyroptosis by cleaving GSDMD [15]. Different from necroptosis and apoptosis, pyroptosis is a lytic form of cell death and is caused by the GSDMD-formed pores in the plasma membrane $[16,17]$, and this programmed cell death is also essential for immune defenses and diseases.
NLRP1 is responsible for the host susceptibility to Toxoplasma infection, and knockdown of the NLRP1 gene directly influences inflammasome related-cell death and parasite replication in Toxoplasma-infected rat macrophages [18]. NLRP3 and other inflammasome components also play protective roles in the host response to $T$. gondii infection [19]. However, the inflammasome responses in $N$. caninum infection are poorly understood. Therefore, this is the first study to focus on whether the inflammasome participates in innate immune recognition and its role in the host defense against $N$. caninum.

\section{Methods}

\section{Animals}

Female C57BL/6 mice (6-8 weeks old) were obtained from the Laboratory Animal Center of Jilin University (Changchun, China). Nlrp3 $3^{-/-}$(knockout) mice were purchased from The Jackson Laboratory (Bar Harbor, ME, USA). The mice were maintained in isolator cages, with a light/dark cycle of $12 \mathrm{~h}$, and with sterile food and water in the animal house of the Laboratory Animal Center of Jilin University.

\section{Parasites and cells}

Neospora caninum tachyzoites (Nc-1) were maintained by serial passages in Vero cells, and free $N$. caninum were obtained from the cell cultures as described previously [20]. Briefly, N. caninum tachyzoites were harvested after $80 \%$ lysis of the host cells by mechanical disruption with a 27 gauge needle and centrifuged at $1500 \times g$ for $30 \mathrm{~min}$ to remove host cell debris by gradient density centrifugation with a $40 \%$ Percoll (GE Healthcare, Uppsala, Sweden) solution (v/v). The pellet of the parasite suspension was collected and washed twice with RPMI-1640 (centrifuged at 1000× $g$ for $10 \mathrm{~min}$ ), and the $N$. caninum concentration was determined in a hemocytometer. Excretory secretory antigens (ESAs) of $N$. caninum tachyzoites were prepared, and $2 \times 10^{8}$ tachyzoites were incubated at $37{ }^{\circ} \mathrm{C}$ for $3 \mathrm{~h}$ in $2 \mathrm{ml}$ of serum-free RPMI-1640 (Life Technologies, Grand Island, NY) containing penicillin-streptomycin. After centrifugation for $10 \mathrm{~min}$ at $1000 \times g$, the ESAscontaining supernatant was filtered through a $0.22-\mu \mathrm{m}$ Millipore membrane and stored at $-80{ }^{\circ} \mathrm{C}$ until use [21].

The mice were inoculated intraperitoneally with $3 \mathrm{ml}$ of $5 \%$ thioglycollate medium for 4 days, and macrophages from the peritoneal cavity were harvested in cold PBS [22]. Peritoneal macrophages (PMs) were cultured in complete medium (RPMI, $2 \mathrm{mM}$ glutamine, $1 \mathrm{mM}$ sodium pyruvate, $10 \mathrm{mM}$ HEPES and $100 \mu \mathrm{g}$ penicillinstreptomycin) plus $10 \%$ fetal bovine serum (FBS; BI, Shanghai, China) for $24 \mathrm{~h}$ in 6 -well plates at $1 \times 10^{6}$ cells/well. 
Probing the mouse inflammasome RT profiler PCR arrays PMs were infected with $N$. caninum at a multiplicity of infection (MOI) of 3:1 (parasite:cell) for $12 \mathrm{~h}$ and $24 \mathrm{~h}$ and harvested with $1 \mathrm{ml}$ of TRIzol reagent (Life Technologies, Carlsbad, USA) for total RNA extraction according to the manufacturer's instructions. After quantification using a Nanodrop ND-2000 apparatus (Thermo Scientific, Wilmington, USA), $2 \mu \mathrm{g}$ of total RNA was used for cDNA synthesis using the $\mathrm{RT}^{2}$ First Strand Kit (SA Biosciences/Qiagen, Shanghai, China).

The 96-well Mouse Inflammasome RT Profiler PCR Arrays (SA Biosciences/Qiagen, Shanghai, China), containing primer pairs for 84 key genes involved in the NLR inflammasome pathway, were probed with cDNA template in the presence of SuperArray PCR master mix (Qiagen, Shanghai, China), and the PCR analysis was performed on a Bio-Rad iCycler (USA). The arrays were probed with cDNA from 3 treatments $(12 \mathrm{~h}, 24 \mathrm{~h}$ and the control group) in duplicate, and the results were analyzed by Excel-based PCR Array Data Analysis software (SA Biosciences, Shanghai, China) for threshold cycle (Ct) value determination. The $\mathrm{Ct}$ of the genes was normalized to that of housekeeping genes (the average $\mathrm{Ct}$ of Actb, B2m, Gapdh and Hsp90ab1). The relative expression level of each target gene in infected cells was calculated as $2^{-\Delta \Delta \mathrm{Ct}}$ (fold change), where $\Delta \Delta \mathrm{Ct}$ represents the Ct (sample) - Ct (control).

\section{RNA isolation and real-time PCR analysis}

Total RNA was extracted from infected peritoneal macrophages $(\mathrm{MOI}=3: 1)$ at $12 \mathrm{~h}$ post infection (p.i.) using TRIzol reagent according to the manufacturer's instructions. All RNA samples were dissolved in $20 \mu \mathrm{l}$ of nuclease-free $\mathrm{H}_{2} \mathrm{O}$ and quantified using a Nanodrop ND-2000 apparatus (Thermo Scientific). cDNA synthesis was performed using 2-3 $\mu \mathrm{g}$ of total RNA prepared as described above in a $20 \mu \mathrm{l}$ final volume using a
PrimeScript $^{\mathrm{Tm}}$ RT Reagent Kit (TaKaRa, Dalian, China) according to the manufacturer's instructions. Real-time PCR was then used for the quantification of murine NLRP3 [23], NLRC4 and NLRC5 (each specific primer is listed in Table 1) mRNA expression levels with FastStart Universal SYBR Green Master (Roche Diagnostics, Mannheim, Germany). The qPCR was performed as follows: denaturation at $95{ }^{\circ} \mathrm{C}$ for $5 \mathrm{~min}$, followed by amplification with 40 cycles of $95{ }^{\circ} \mathrm{C}$ for $10 \mathrm{~s}$ and $60{ }^{\circ} \mathrm{C}$ for $30 \mathrm{~s}$. The data were normalized to murine $\beta$-actin, and the fold change was calculated as $2^{-\Delta \Delta C t}$, where $\Delta \Delta \mathrm{Ct}$ represents the Ct (sample) - Ct (control).

\section{Stimulation}

At $3 \mathrm{~h}$ prior to infection, the medium was changed to complete medium (RPMI) plus 1\% fetal bovine serum with or without $100 \mathrm{ng} / \mathrm{ml}$ ultrapure lipopolysaccharide (LPS; Sigma, Shanghai, China). The PMs were stimulated with $N$. caninum for the indicated times $(1-24 \mathrm{~h})$ at various multiplicities of infection $(\mathrm{MOI}=1: 1,3: 1$, and 5:1). PMs treated with medium alone or LPS were used as negative controls, and cells treated with ATP (5 mM, 30 min; Sigma, Shanghai, China) were used as positive controls, as extracellular ATP is a conventional NLRP3 inflammasome agonist [14].

To monitor the role of the inflammasome in response to $N$. caninum infection in PMs, PMs were pre-treated with $100 \mu \mathrm{M}$ Ac-YVAD-CHO (an inhibitor of caspase-1 and -4; Enzo Life Science, Lausen, Switzerland), $100 \mu \mathrm{M}$ zVAD-fmk (an inhibitor of pan-caspase; Selleck, Shanghai, China) or $100 \mu \mathrm{M}$ glyburide (an inhibitor of NLRP3 by inhibiting $\mathrm{K}^{+}$efflux; Selleck, Shanghai, China) for $45 \mathrm{~min}$ before stimulation, and the PMs were then stimulated with LPS priming plus $N$. caninum for $12 \mathrm{~h}$ at an MOI of 3:1 (parasite:cell), and PMs cultured with 0.2\% DMSO were used as a negative control.

Table 1 Primer sequences used in this study

\begin{tabular}{|c|c|c|c|c|}
\hline Gene & Accession number & Primer sequence (5'-3') & Size (bp) & Reference \\
\hline \multicolumn{5}{|l|}{ Murine } \\
\hline \multirow[t]{2}{*}{ NLRP3 } & NM_145827 & Forward: AGAAGAGACCACGGCAGAAG & 102 & [23] \\
\hline & & Reverse: CCTTGGACCAGGTTCAGTGT & & \\
\hline \multirow[t]{2}{*}{ NLRC4 } & NM_001033367.3 & Forward: CTTGGCCAGGAGAGCCTTG & 153 & \\
\hline & & Reverse: GGGCTCGTCTGTTGTTCCTT & & \\
\hline \multirow[t]{2}{*}{ NLRC5 } & NM_001033207.3 & Forward: GCTGAGAGCATCCGACTGAA & 157 & \\
\hline & & Reverse: GGTGGATGACCTCAGGGTTG & & \\
\hline \multirow[t]{2}{*}{ ACTB } & NM_007393.5 & Forward: ACCTTCTACAATGAGCTGCG & 147 & \\
\hline & & Reverse: CTGGATGGCTACGTACATGG & & \\
\hline \multicolumn{5}{|c|}{ Neospora caninum } \\
\hline \multirow[t]{2}{*}{ NC5 } & X84238 & Forward: ACTGGAGGCACGCTGAACAC & 76 & [25] \\
\hline & & Reverse: AACAATGCTTCGCAAGAGGAA & & \\
\hline
\end{tabular}




\section{Cytokine measurement and LDH assay}

Supernatants were harvested at various time points for cytokine measurement and in select experiments for the lactate dehydrogenase (LDH) assay (Roche Diagnostics, Mannheim, Germany) according to the manufacturer's protocol. The percentage of LDH release, as a measure of cell death, was calculated as follows: (LDH infected - LDH control $) /(\mathrm{LDH}$ total lysis - LDH control $) \times 100$. The remaining supernatants were stored at $-20{ }^{\circ} \mathrm{C}$ for use in an IL-1 $\beta$ enzyme-linked immunosorbent assay (ELISA) by a mouse IL-1 $\beta$ Ready-Set-Go Kit (eBioscience, San Diego, USA).

\section{Immunoblot analysis}

Cell lysates were extracted from infected macrophages in radioimmunoprecipitation assay (RIPA) buffer with complete protease inhibitor, phenylmethylsulfonyl fluoride (PMSF) and phosphatase inhibitor cocktail (all from Sigma). Cell culture supernatants were precipitated by methanol and chloroform to obtain protein samples as previously described [24]. Briefly, the supernatants were mixed with an equal volume of cold methanol and 1/4 volume of cold chloroform and then centrifuged at $13,000 \times g$ for $10 \mathrm{~min}$ at $4{ }^{\circ} \mathrm{C}$. The upper phase was discarded, $1 \mathrm{ml}$ of methanol was added, and the mixture was then centrifuged for $10 \mathrm{~min}$ at $13,000 \times \mathrm{g}$. The protein pellets were dried at room temperature and dissolved in $1 \%$ SDS buffer. The protein samples were separated and analyzed by SDS-PAGE and immunoblot. Membranes were blocked in 5\% skim milk, incubated overnight at $4{ }^{\circ} \mathrm{C}$ with primary antibodies and visualized with secondary HRP-conjugated antibodies (Proteintech, Wuhan, China). The primary antibodies used were anti-mouse IL-1 $\beta$ (AF-401, R\&D, Minneapolis, USA), antimouse caspase-1 (p20) (AG-20B-0042, Adipogen, Liestal, Switzerland), anti-NLRP3 (AG-20B-0014, Adipogen, Liestal, Switzerland) and anti-mouse $\beta$-actin (60008-1, Proteintech, Wuhan, China).

\section{DNA extraction and detection of $N$. caninum by qPCR}

The parasite replication in the infected cells was monitored as previously described [25] by performing a quantitative real-time PCR (qPCR) analysis of the parasite DNA. Genomic DNA from $10^{7}$ tachyzoites of N. caninum and total DNA from infected cells were extracted using a Genomic DNA Extraction Kit (TIANGEN, Beijing, China) according to the manufacturer's protocol. The total DNA (100 ng) from infected cells was used as a template in qPCR analyses with FastStart Universal SYBR Green Master, and oligonucleotide primers specific for the Nc5 sequence of $N$. caninum (Table 1) were used to amplify a 76-bp DNA fragment. The parasite number was determined by a standard curve performed with DNA isolated from $N$. caninum tachyzoites, ranging from 5 to $5 \times 10^{5}$ parasites, included in each run. The data were analyzed and expressed as log10 parasites per $100 \mathrm{ng}$ of total DNA.

\section{Confocal microscopy}

PMs were plated on coverslips in 6-well plates, pretreated with LPS $(100 \mathrm{ng} / \mathrm{ml})$ for $3 \mathrm{~h}$, and then stimulated with $N$. caninum tachyzoites for $10 \mathrm{~h}(\mathrm{MOI}=3)$. After washing two times with PBS, the cells were fixed with $4 \%$ paraformaldehyde in PBS for $15 \mathrm{~min}$ and then washed three times with PBS. After a 20-min permeabilization with $0.5 \%$ Triton $\mathrm{X}-100$ in PBS and blocking with $3 \% \mathrm{BSA}$ in PBS for $30 \mathrm{~min}$ at room temperature, the cells were incubated with an antibody against NLRP3 (Adipogen; 1:200) overnight at $4{ }^{\circ} \mathrm{C}$. After washing with PBST, the cells were incubated with secondary antibody (Proteintech) for $1 \mathrm{~h}$ at room temperature. F-actin was stained with TRITC Phalloidin, and mammalian nuclei were stained with DAPI. For visualization of live or dead infected cells, the PMs were seeded in 96-well plates, and after stimulation for $12 \mathrm{~h}$ the cells were stained using a LIVE/DEAD Cell Imaging Kit (Life Technologies, Eugene, USA) for $15 \mathrm{~min}$. The cells were analyzed on an Olympus FV1000 Laser Scanning Confocal microscope (Japan) with a $100 \times$ objective for NLRP3 imaging and 10x objective for live/dead cell imaging.

\section{Statistics}

Data analysis was performed using Prism 5.0 (GraphPad Software, Inc.) and expressed as the mean \pm SD. To evaluate the differences between two groups (experimental group $v s$ control group), the two-tailed $t$-test was used. Significance is shown by ${ }^{*} P<0.05$, **P $P<0.01, * * * 0.001$.

\section{Results \\ Inflammasome-related gene expression in N. caninum- infected peritoneal macrophages}

Murine peritoneal macrophages were incubated with $N$. caninum for 12 or $24 \mathrm{~h}$ and probed for the expression of 84 genes using the Mouse Inflammasome RT Profiler PCR Arrays. Of the 84 probed genes, 40 (32 upregulated and 8 downregulated) and 33 (24 upregulated and 9 downregulated) genes in $N$. caninum-infected PMs were differentially expressed at 12 and 24 h p.i., respectively, in comparison to the expression observed in the control cells. The expression of 16 NOD-like receptor (sensor protein) genes were especially noted, and the results exhibited that 8 (6 upregulated and 2 downregulated) and 6 (2 upregulated and 4 downregulated) of these genes showed differential expression at 12 and $24 \mathrm{~h}$ p.i., respectively (Fig. 1a). The NLRP3 (41.90 $\pm 4.63,12 \mathrm{~h} ; 17.56$ $\pm 2.45,24 \mathrm{~h})$ and NLRC5 $(2.8 \pm 0.47,12 \mathrm{~h} ; 2.73 \pm 0.75,24 \mathrm{~h})$ 

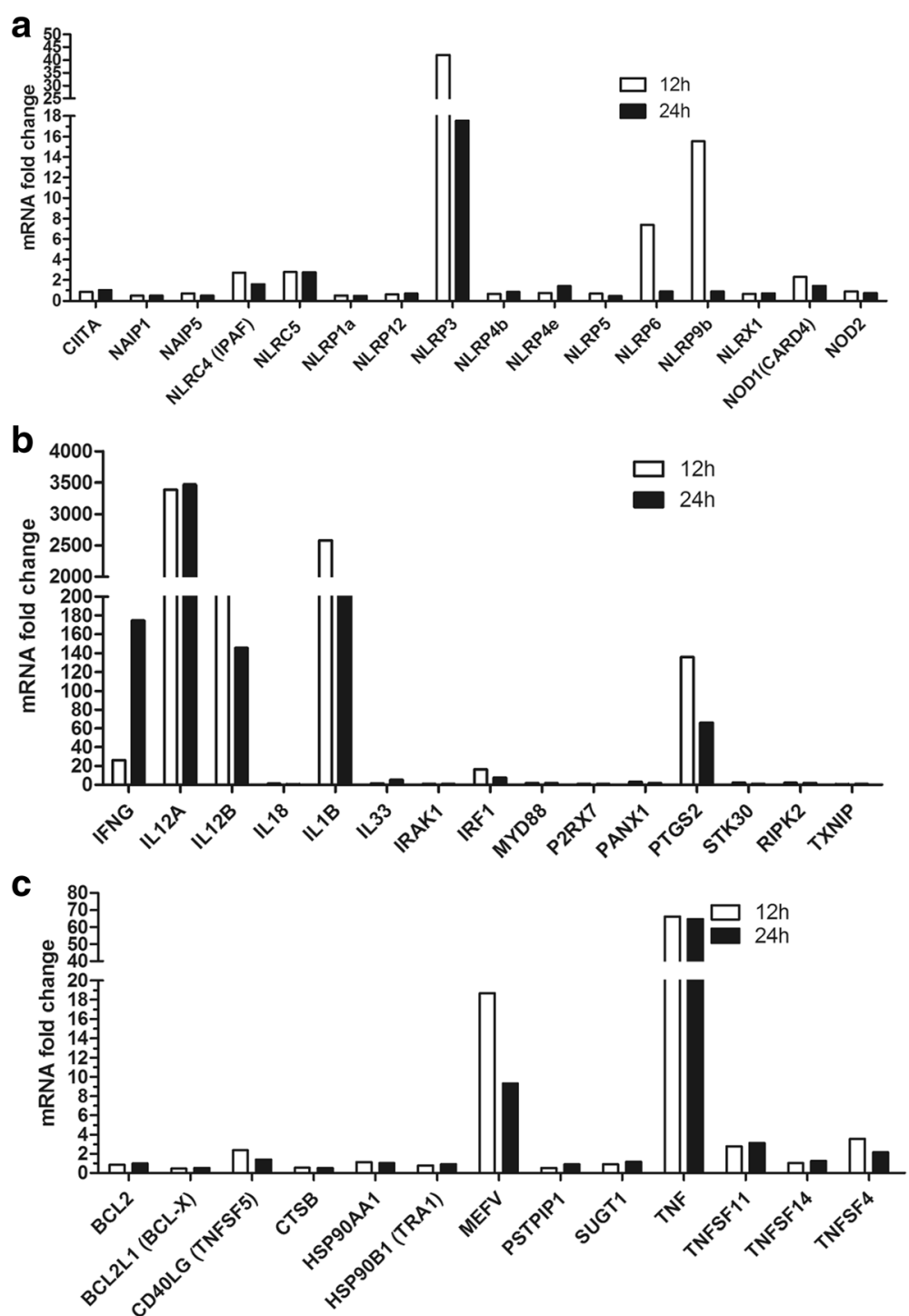

Fig. 1 Inflammasome-related gene expression in mouse peritoneal macrophages in response to N. caninum infection. The 96-well RT Profiler Mouse Inflammasome PCR Arrays (Qiagen) were probed with cDNA from peritoneal macrophages infected with $N$. caninum (MOI = 3:1, parasite:cell) for $12 \mathrm{~h}$ or $24 \mathrm{~h}$ (without LPS priming). The Ct values from the qPCR data were analyzed, and the relative expression level of each target gene in the samples was calculated using fold change. Fold-Change $\left(2^{-\Delta \Delta c t}\right)$ is the normalized gene expression $\left(2^{-\Delta C t}\right)$ in the Test Sample divided the normalized gene expression $\left(2^{-\Delta C t}\right)$ in the Control Sample. In the PCR arrays, 84 inflammasome-related genes were measured, and the expression levels of key genes in three functional groups are shown. a Relative expression levels of 16 NOD-like receptor genes. b Relative expression levels of downstream signaling genes in inflammasome-mediated responses. c Relative expression levels of inflammasome negative regulation genes. The data are representative of two independent experiments

genes were upregulated at both 12 and $24 \mathrm{~h}$ p.i. In addition, the NAIP1 $(0.46 \pm 0.12,12 \mathrm{~h} ; 0.48 \pm 0.09,24 \mathrm{~h})$ and NLRP1a $(0.46 \pm 0.08,12 \mathrm{~h} ; 0.48 \pm 0.13,24 \mathrm{~h})$ genes were downregulated at both 12 and $24 \mathrm{~h}$ p.i. Meanwhile, the expression levels of downstream signaling genes in the inflammasomemediated response to $N$. caninum infection showed that IL-1B (IL-1ß), IFNG (IFN- $\gamma$ ), IL-12A (IL-12p35/a), and IL12B (IL-12p40) were extremely upregulated (Fig. 1b), while upregulation of IL-18 was not observed. The expression levels of inflammasome negative regulation genes showed that the expression of 6 (5 upregulated and 1 downregulated) and 5 (4 upregulated and 1 downregulated) genes was changed at 12 and $24 \mathrm{~h}$ p.i., respectively. The MEFV (FMF/TRIM20), TNF (TNF- $\alpha$ ), TNFSF11 (Ly1091/ODF), and TNFSF4 (Ath1/CD134L) genes were upregulated at both 12 and 24 h p.i. (Fig. 1c). These results indicate that many types of genes in the inflammasome pathway participated in the response to $N$. caninum infection, several receptor genes are upregulated, and NLRP3 is the most upregulated sensor protein. 
Secretion of inflammasome-mediated IL- $1 \beta$ in $N$. caninuminfected peritoneal macrophages

To verify the results regarding upregulated receptor genes (12 $\mathrm{h}$ p.i.) obtained in the PCR array analysis (Fig. 1a), the expression levels of NLRP3, NLRC4 and NLRC5 in N. caninum-infected PMs at $12 \mathrm{~h}$ p.i. were detected by qPCR
(Fig. 2a). The qPCR results confirmed that NLRP3 was the most upregulated receptor. To examine inflammasome activation, the expression of NLRP3, processing and secretion of caspase-1, and production of the caspase-1 substrate IL-1 $\beta$ were examined in macrophages stimulated with $N$. caninum. In unstimulated macrophages, caspase-

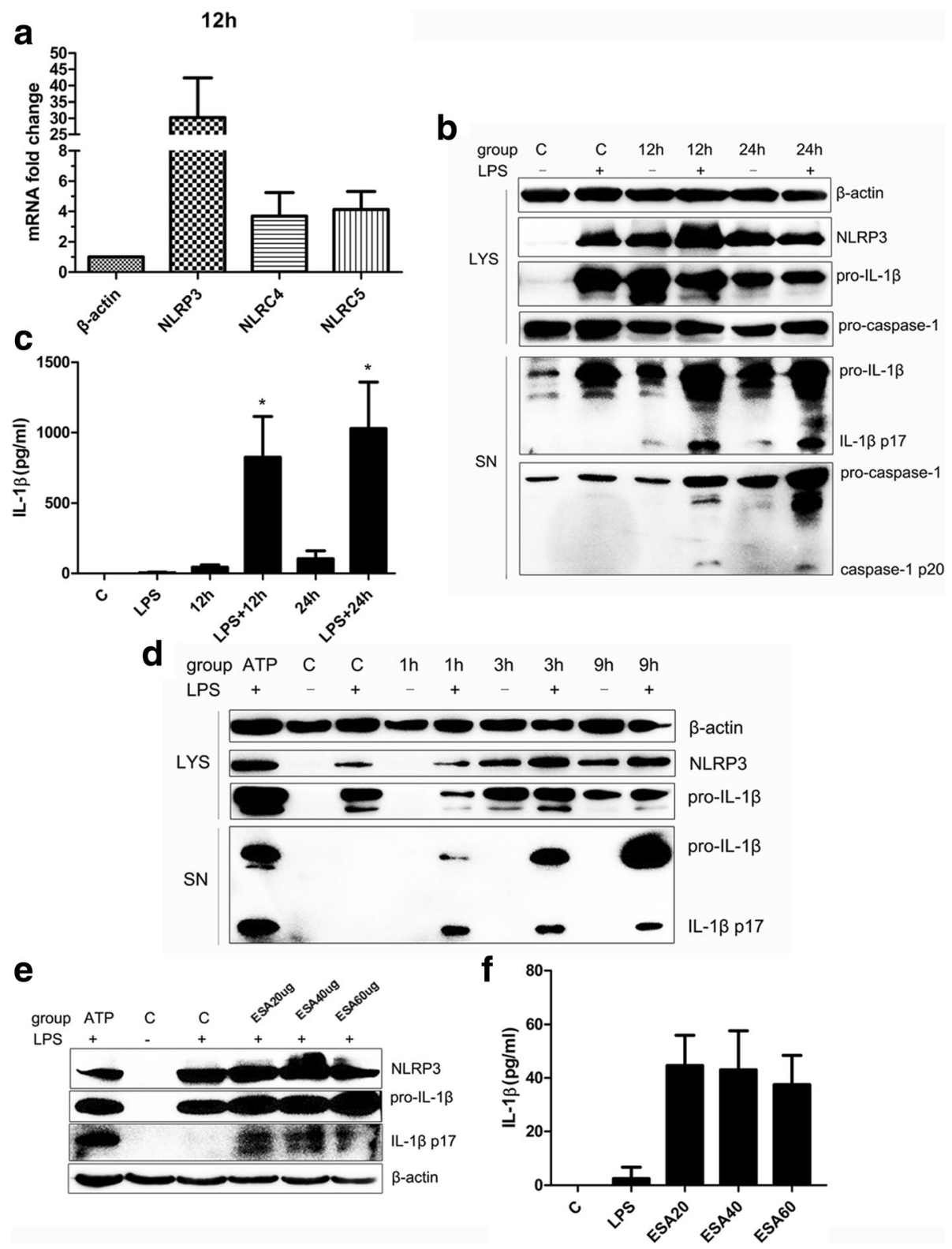

Fig. 2 Secretion of inflammasome-mediated IL-1ß is induced in mouse peritoneal macrophages infected by $N$. caninum. a Confirmation of some upregulated genes indicated in the inflammasome PCR array. Peritoneal macrophages (without LPS priming) were stimulated with $N$. caninum tachyzoites (MOI = 3:1, parasite:cell) for $12 \mathrm{~h}$, and the expression levels of the NLRP3, NLRC4 and NLRC5 genes were measured by qPCR. $\mathbf{b}$-f With or without LPS priming (indicated + or - in the figures), peritoneal macrophages were incubated with $N$. caninum tachyzoites (MOI $=3: 1$, parasite:cell) for the indicated time or $\mathrm{N}$. caninum tachyzoites excretory-secretory antigens (ESAs) for 12 h; LPS primed peritoneal macrophages were incubated with ATP $(5 \mathrm{mM})$ for 30 min as positive control. b, d e expression of NLRP3, processing of caspase-1 and secretion of IL- $\beta$ were analyzed by immunoblot. $\mathbf{c}$, f IL-1 $\beta$ production in supernatants was measured by ELISA. Abbreviations: C, control; SN, supernatants; LYS, cell lysates; ESA, excretory secretory antigens. The data are representatives of three independent experiments and presented as the mean $\pm \operatorname{SD}\left({ }^{*} P<0.05 ;{ }^{* *} P<0.01 ;{ }^{* *} P<0.001\right.$ vs negative control) 
1 is a $45 \mathrm{kDa}$ pro-enzyme. When recruited to an activated inflammasome platform, caspase- 1 begins autoproteolysis to become the active form (p20 and p10 subunits) and cleaves pro-IL-1 $\beta(31 \mathrm{kDa})$ into active IL-1 $\beta(17 \mathrm{kDa})$ [26]. PMs with or without LPS priming were incubated with $N$. caninum (3:1, parasite:cell), and at 12 and $24 \mathrm{~h}$ p.i. the results showed a gradual increase in IL- $1 \beta$ production (Fig. 2b, c). In the absence of LPS priming, NLRP3 expression together with the secretion of active IL-1 $\beta$ p17 (bottom immunoblot) could be induced in $N$. caninum-infected PMs, and these data support the transcriptional upregulation of NLRP3 and IL-1 $\beta$ in Fig. 1, but it was difficult to detect active caspase- 1 p20 (bottom immunoblot) (Fig. 2b). However, in the presence of LPS priming, more robust production of IL-1 $\beta$ and secretion of processed caspase-1 p20 subunits were observed (Fig. 2b). Moreover, in the presence of LPS priming, N. caninum-infected PMs released a substantially higher amount of IL- $1 \beta$ than that observed with only $N$. caninum infection, and in both the absence and presence of LPS priming, the production of IL- $1 \beta$ was gradually increased at 12 and 24 h p.i. in $N$. caninum-infected PMs (Fig. 2b, c). Although the expression of NLRP3 and pro-IL-1 $\beta$ can be observed, N. caninum infection was not sufficient to trigger the cleavage of IL- $1 \beta$ in PMs at 3 and $9 \mathrm{~h}$ p.i. in the absence of LPS priming (Fig. $2 \mathrm{~d}$ ). In contrast, in the presence of LPS priming, the cleavage of IL- $1 \beta$ can be observed as early as at $1 \mathrm{~h}$ p.i. in $N$. caninum-infected PMs, and LPS treatment alone could not induce cleavage of IL-1 $\beta$ in PMs (Fig. $2 d$ ). These data indicate that the processing and release of IL- $1 \beta$ induced in macrophages by $N$. caninum occurs in a timedependent manner, and LPS priming is also essential for $N$. caninum-triggered inflammasome activation. In addition, IL-1 $\beta$ cleavage could be induced by treatment with excretory secretory antigens (ESAs) of N. caninum tachyzoites at $12 \mathrm{~h}$ p.i. in the presence of LPS priming (Fig. 2e, f).

\section{IL-1 $\beta$ production and cell death in $N$. caninum-infected peritoneal macrophages}

To further explore the inflammasome response to $N$. caninum, LPS-primed PMs were infected with different numbers of parasites. The cell death and distribution of NLRP3 in $N$. caninum-infected PMs were monitored. Further increases in IL-1 $\beta$ release at $12 \mathrm{~h}$ p.i. depended on incubation with higher number of parasites (MOI = 1:1, 3:1, and 5:1), and processed and secreted caspase-1 (caspase-1 p20) could also be detected in cell supernatants (Fig. 3a, b). Similarly, this phenomenon occurred in N. caninum-infected PMs at 3 h p.i. (Fig. 3c, d). Cell death was observed by both an LDH assay and a live/ dead cell imaging assay at $12 \mathrm{~h}$ p.i. and was consistently dependent on the number of parasites used to infect the cells (Fig. 3e, f). In unstimulated macrophages, NLRP3 is localized throughout the cytoplasm, whereas in macrophages incubated with ATP, NLRP3 is redistributed to form puncta $[14,26]$. Similarly, NLRP3 was localized to the perinuclear space in puncta and slightly distributed to the parasitophorous vacuole in PMs infected with $N$. caninum (3:1, parasite:cell) at $10 \mathrm{~h}$ p.i. (Fig. 4a). IL-1 $\beta$ release from $N$. caninum-infected PMs at 10 h p.i. was also observed (Fig. 4b, c), together with NLRP3 redistribution. These data indicated that NLRP3 inflammasome activation participated in the response to $N$. caninum infection.

\section{Role of the inflammasome in IL-1 $\beta$ release and control of $N$. caninum replication}

To determine whether the inflammasome plays a role in IL- $1 \beta$ release and the control of parasite replication in macrophages infected by $N$. caninum, PMs were pretreated with the pan-caspase inhibitor zVAD-fmk, the caspase-1-specific inhibitor Ac-YVAD-CHO or the NLRP3 inhibitor glyburide. Pan-caspase inhibition (zVAD) prevented the release of active IL-1 $\beta$, and caspase-1 inhibition (YVAD) decreased the secretion of active IL- $\beta$. Although NLRP3 was expressed, glyburide inhibition led to failed IL- $\beta$ maturation (Fig. 5a, b). For parasite replication in infected PMs, the parasite burden was assessed by qPCR with total DNA (100 ng) from infected cells. We observed that the parasite burden was significantly higher in the pan-caspase inhibition group than in the control group (Fig. 5c). Meanwhile, these inhibitors did not influence the viability of $N$. caninum at $12 \mathrm{~h}$ (see Additional file 1: Figure S1). These data indicate that the secretion of IL- $1 \beta$ in response to $N$. caninum is an inflammasome-mediated activity, and the inflammasome is required for the control of intracellular parasite replication.

To verify whether the NLRP3 inflammasome was required in host response to $N$. caninum, PMs isolated from $N l r p 3^{-/}$mice were infected with $N$. caninum $(\mathrm{MOI}=3: 1)$ at $12 \mathrm{~h}$ p.i. plus LPS priming. Results showed that release of active IL- $1 \beta$ in the supernatant was greatly reduced and cleavage of caspase- 1 was inhibited in $\mathrm{Nlrp3}^{-/-}$PMs infected with N. caninum, compared to the amount present in the supernatant of wildtype (WT) infected PMs (Fig. 5d, e). Therefore, N. caninum induced IL-1 $\beta$ release and caspase- 1 cleavage is mainly dependent on the NLRP3 inflammasome. These data confirmed the importance of NLRP3 inflammasome in $N$. caninum triggered inflammasome activation.

\section{Discussion}

Neospora caninum is an intracellular protozoan parasite that causes severe economic losses in the dairy and beef industries. At present, aside from management control measures, no effective immunological approach is used 


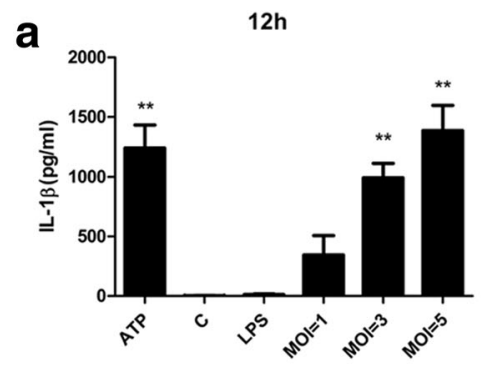

C

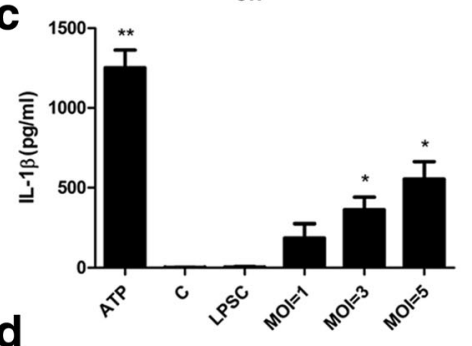

d
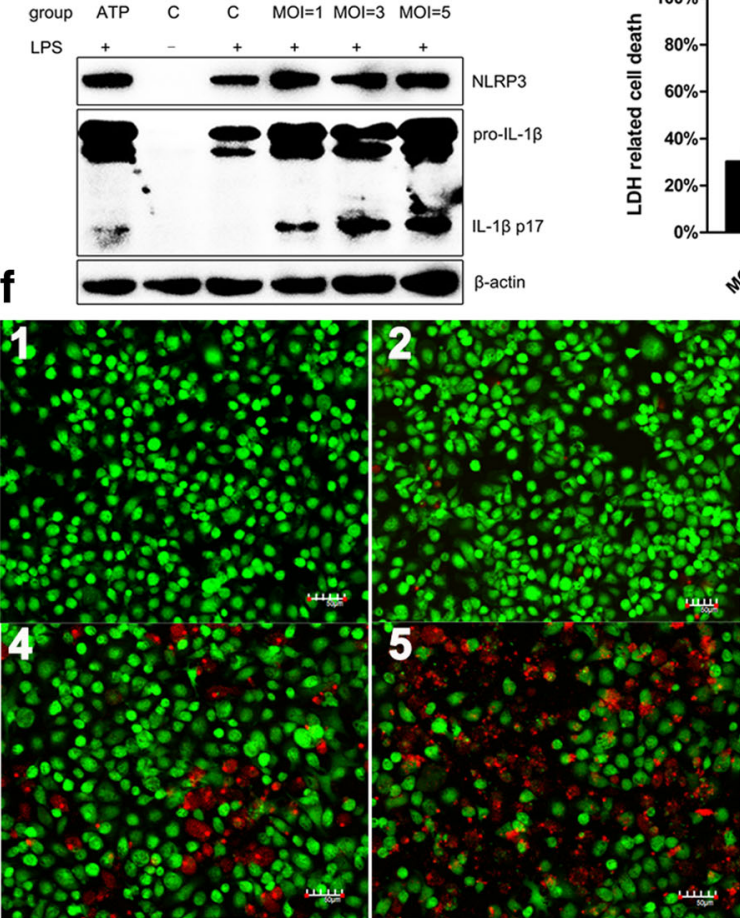

Green=live cells Red=dead cells b group ATP $\quad \mathrm{C} \quad \mathrm{C} \quad \mathrm{MOI}=1 \mathrm{MOI}=3 \mathrm{MOI}=5$

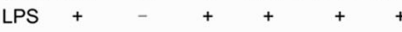

LYS
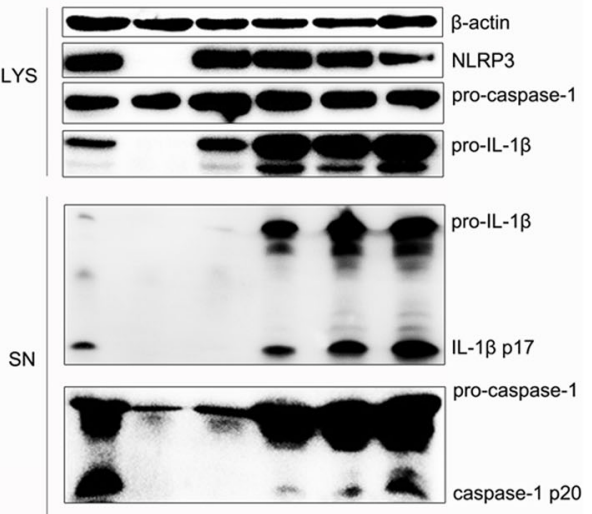

e

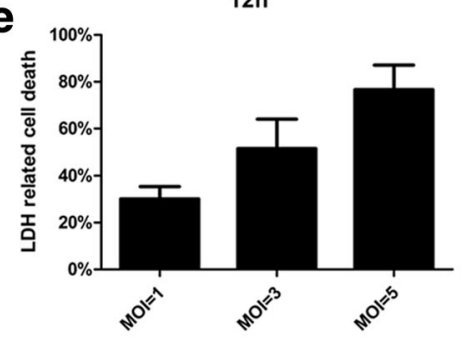

Fig. $3 \mathrm{~L}-1 \beta$ production and cell death induced by N. caninum depends on the parasite amount in peritoneal macrophages. Peritoneal macrophages primed with LPS were incubated with the indicated number ( $\mathrm{MOI}=$ parasite:cell) of $\mathrm{N}$. caninum tachyzoites for $12 \mathrm{~h}(\mathbf{a}, \mathbf{b}, \mathbf{e}, \mathbf{f})$ or $3 \mathrm{~h}(\mathbf{c}, \mathbf{d})$, or incubated with ATP $(5 \mathrm{mM})$ for $30 \mathrm{~min}$ as positive control. a, $\mathbf{c}$ The production of IL-1 $\beta$ in the supernatants was measured by ELISA. $\mathbf{b}$, $\mathbf{d}$ The secretion of the processed p20 subunit and active IL-1 1 (p17) and the expression of NLRP3 were detected in cell extracts (LYS) or supernatants (SN) by immunoblot. e Supernatants were harvested at $12 \mathrm{~h}$ p.i., and LDH release was detected to measure cell death. $\mathbf{f}$ At $12 \mathrm{~h}$ after infection with $\mathrm{N}$. caninum tachyzoites (MOI=1:1 (4), 3:1 (5), 5:1 (6), parasite:cell), peritoneal macrophages with medium only (1), with $100 \mathrm{ng} / \mathrm{ml} \mathrm{LPS} \mathrm{treatment} \mathrm{(2),} \mathrm{and} 1 \mathrm{~h}$ after treatment with $5 \mathrm{mM}$ ATP (3) were stained with a LIVE/DEAD Cell Imaging Kit for $15 \mathrm{~min}$ and imaged at a magnification of $\times 10$. Live (green) and dead (red) cells in each group are shown. Abbreviations: C, control; SN, supernatants; LYS, cell lysates; MOI, multiplicity of infection. The data are representative of three independent experiments and presented as the mean \pm SD $\left({ }^{*} P<0.05 ;{ }^{* *} P<0.01 ;{ }^{* *} P<0.001\right.$ vs negative control) Scale-bars: $50 \mu \mathrm{m}$

to control neosporosis; therefore, understanding the innate immune recognition process for $N$. caninum will not only mechanistically define/improve the host resistance to this infectious disease but also help guide immune-mediated preventive approaches for $N$. caninum infection. In this study, we have utilized primary 


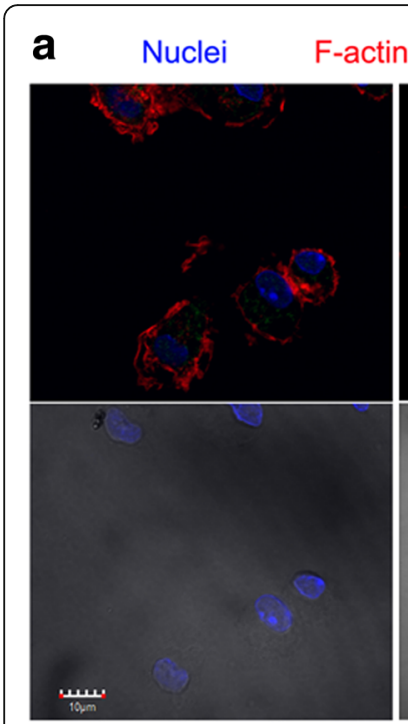

unstimulated

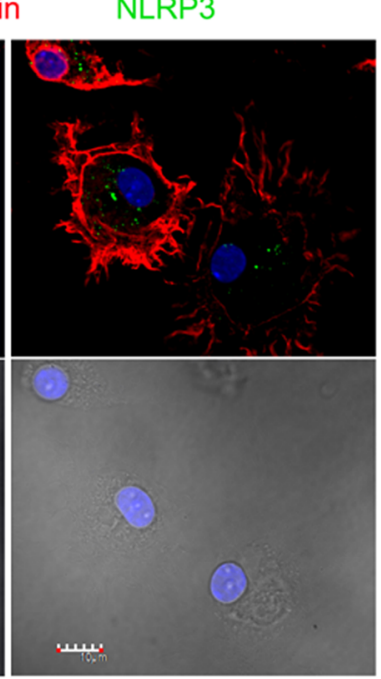

ATP

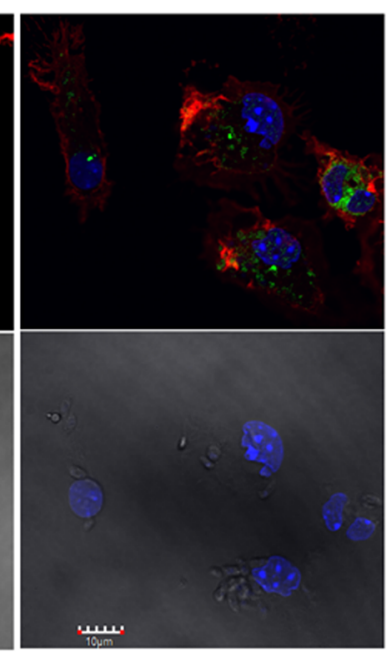

$\mathrm{Nc}$

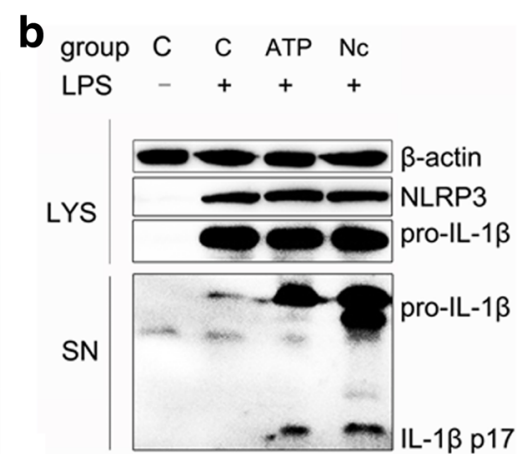

C

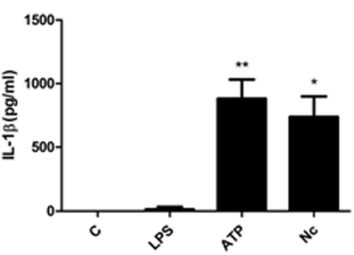

Fig. 4 NLRP3 inflammasome activation in N. caninum infection. Peritoneal macrophages primed with LPS were incubated with N. caninum tachyzoites (Nc) (MOI = 3:1, parasite:cell) for $10 \mathrm{~h}$ or ATP $(5 \mathrm{mM})$ for $30 \mathrm{~min}$. a The localization of NLRP3 and F-actin after stimulation with N. caninum or ATP. b The NLRP3 expression and the secretion of IL-1 $\beta$ after stimulation with $N$. caninum (10 h) were determined by immunoblot analysis. c The production of IL-1 $\beta$ in the supernatants was measured by ELISA. Abbreviations: C, control; SN, supernatants; LYS, cell Iysates; Nc, N. caninum. The data are representative of three independent experiments and presented as the mean $\pm \mathrm{SD}\left({ }^{*} P<0.05 ;{ }^{*} P<0.01 ;{ }^{* *} P<0.001\right.$ vs negative control). Scale-bars: $10 \mu \mathrm{m}$

macrophages and employed inhibitory approaches to investigate whether the inflammasome was activated and its role in $N$. caninum infection. We found that macrophages responded to $N$. caninum infection with inflammasome activation and IL-1 $\beta$ secretion.

NLR inflammasome-related genes participated in the host response to $N$. caninum. Activation of the inflammasome requires a priming step, typically provided by LPS pre-treatment, which leads to the expression of sensor molecules and pro-forms of inflammatory cytokines (pro-IL-1 $\beta$ and pro-IL-18) through the NF-kB pathway [27]. In our study, the data demonstrated that several sensor molecules, especially NLRP3, were upregulated in PMs infected with $N$. caninum without LPS priming because the NF- $\mathrm{BB}$ pathway can be activated by $N$. caninum through TLR3 [5], TLR2 [9] and NOD2 [7]. The NLRP3 inflammasome senses and reacts to infection by numerous bacteria, viruses, fungi, and parasites, and this response can be protective for the host. With the activation of the inflammasome, activated caspase- 1 proteolytically cleaves pro-IL1 $\beta$ and pro-IL-18 into active forms, and these secretions trigger pro-inflammatory and anti-microbial responses [11]. Macrophages express little or no pro-IL-1 $\beta$, so IL-1 $\beta$ secretion includes two steps: pro-IL-1 $\beta$ induction and pro-IL-1 $\beta$ processing. The induction of pro-IL-1 $\beta$ is mediated through the transcriptional activation of the IL- $1 \beta$ gene in response to microbial stimulation via TLRs and NOD2 [8]. In $N$. caninum-infected PMs, IL-1 $\beta$ was extremely transcriptionally upregulated, and this step was the prerequisite for inflammasome activation [11]. Therefore, the upregulation of IL-1 $\beta$ and NLRP3 led us to explore the process of IL-1 $\beta$ secretion and NLRP3 inflammasome activation.

In addition, the IFNG (IFN- $\gamma$ ), IL 12B (IL-12p40), IL 12A (IL-12p35/a) and TNF (TNF- $\alpha$ ) genes were extremely upregulated. Higher levels of IFN- $\gamma$ and IL-12 are triggered in $N$. caninum-infected macrophages [28] and in $N$. caninum-infected mice [20], and they are critical cytokines for host resistance to $N$. caninum [29-32]. The production of TNF- $\alpha$ is also essential in controlling $N$. caninum infection $[31,33,34]$. In addition, similar to LPS, TNF- $\alpha$ is sufficient for NLRP3 inflammasome priming $[35,36]$.

A $T$. gondii study has shown a dual role for the inflammasome sensors NLRP1 and NRLP3 in murine resistance. In an in vitro study, the mRNA expression level and secretion of active IL-1 $\beta$ were observed in $T$. gondiiinfected mouse bone marrow-derived macrophages (BMDMs), while neither upregulation nor cleavage of IL-18 were detected. However, in vivo experiments a high level of IL-18 production was observed in serum from $T$. gondii-infected mice, and paradoxically, no measurable IL-1 $\beta$ was detected in the serum [19]. The results of the above in vitro study of $T$. gondii infection were in agreement with our observation that the IL-18 gene was not upregulated. In addition, in future studies, we will focus on whether the phenomenon of IL-1 $\beta$ and 
a

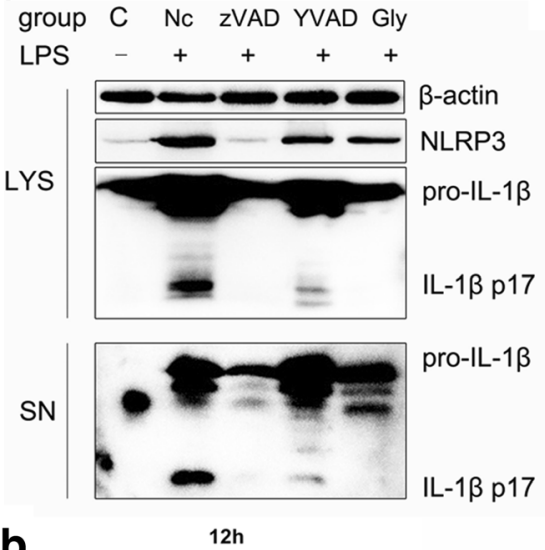

b

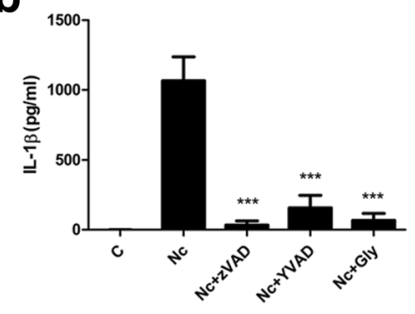

C

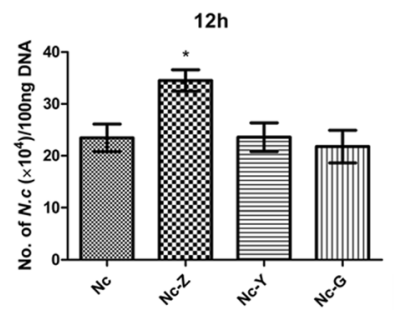

d

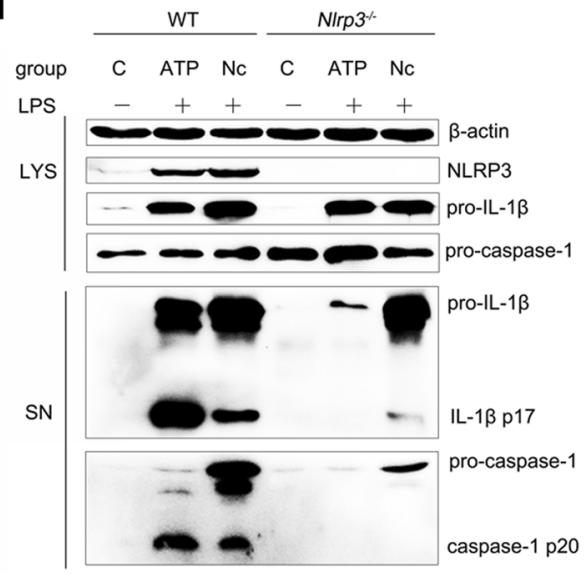

e

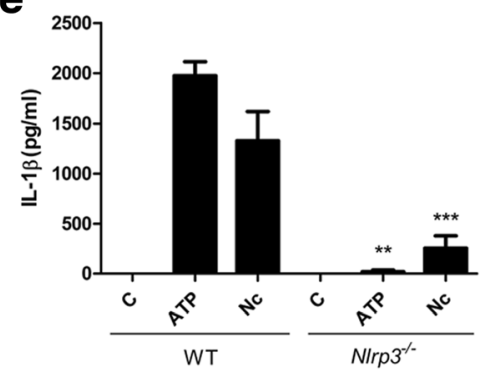

Fig. 5 Role of inflammasomes in IL-1 $\beta$ release and control of $N$. caninum replication. Peritoneal macrophages were pre-treated with $100 \mu M$ zVAD-fmk (ZVAD), $100 \mu \mathrm{M}$ AC-YVAD-CHO (YVAD), or $100 \mu \mathrm{M}$ glyburide (Gly) before stimulation for $45 \mathrm{~min}$, and after LPS priming for $3 \mathrm{~h}$, the macrophages were infected with $N$. caninum ( $M O I=3: 1)$ for $12 \mathrm{~h}$. a The NLRP3 expression and the secretion of IL-1 $\beta$ were determined by immunoblot analysis. $\mathbf{b}$ The production of IL-1 $\beta$ in the supernatants was measured by ELISA. c The number of $\mathrm{N}$. caninum in infected macrophages was monitored after $12 \mathrm{~h}$ by qPCR. $\mathbf{d}$ With LPS priming wild-type (WT) and NIrp3 ${ }^{-/-}$peritoneal macrophages that were infected with N. caninum (MOI = 3:1) for 12 h, and NLRP3 expression, secretion of IL-1 $\beta$ and cleavage of caspase- 1 were determined by immunoblot analysis. $\mathbf{e}$ The production of IL-1 $\beta$ in the supernatants of WT and $\mathrm{NIrp3}^{-1-}$ peritoneal macrophages stimulated with N. caninum was measured by ELISA. Abbreviations: C, control (with $0.2 \%$ DMSO in the inhibitory study); SN, supernatants; LYS, cell lysates; WT, wild-type; Nc, N. caninum; Z, ZVAD-fmk; Y, Ac-WAD-CHO; G, glyburide. The data are representative of three independent experiments and presented as the mean $\pm \mathrm{SD}\left({ }^{*} P<0.05 ;{ }^{* *} P<0.01 ;{ }^{* *} P<0.001\right.$ vs the Nc group or NIrp ${ }^{-1-}$ group vs WT group)

IL-18 production observed in the $T$. gondii study occurs in $N$. caninum-infected mice.

Meanwhile, T. gondii-infected BMDMs from mice lacking ASC, Nlrp1b, Nlrp3, or both Nlrp1b and Nlrp3 were used to determine the critical inflammasome components for IL-1 $\beta$ secretion, and the results showed that the secretion of IL-1 $\beta$ was highly related to the NLRP3 inflammasome. However, in addition to the essential role of NLRP3, the results from $T$. gondii-infected mice deficient in NLRP1 also revealed the protective role of NLRP1 in murine resistance to $T$. gondii [19]. In our study, NLRP3 was mostly upregulated without NLRP1a upregulation in N. caninum-infected PMs, and this result was similar to that observed in $T$. gondii-infected
BMDMs. The NLRP3 inflammasome can sense various stimuli, such as bacteria, viruses, fungi, protozoa, extracellular ATP and uric acid crystals [13], while the activation of NLRP1 inflammasome is more restrictive, its best known agonist being anthrax lethal toxin [37]. However, the activation of both the NLRP3 and NLRP1 inflammasomes could induce IL-1 $\beta$ secretion and pyroptosis [13].

IL-1 $\beta$ secretion in $N$. caninum-infected PMs was timedependent and more rapid and robust with LPS priming (LPS activates the NF-kB pathway). Meanwhile, macrophages responded to a higher number of $N$. caninum parasites with increased IL- $1 \beta$ secretion. It is possible that the IL-1 $\beta$ release mediated by the innate immune system could play a role in controlling $N$. caninum 
infection. Caspase-1-mediated cell death is called pyroptosis, is associated with the loss of plasma membrane integrity and release of DAMPs, and is a pro-inflammatory form of cell death [14] that mainly occurs in macrophages or dendritic cells [15, 38]. Following caspase-1 activation, $N$. caninum-infected peritoneal macrophages (with LPS priming) appeared to trigger cell death, with an increase in membrane permeability (live/dead cell image) and leakage of cytosolic contents (LDH release). The death of $N$. caninum-infected PMs may help the host eliminate the parasite because macrophages could transport $N$. caninum away from the primary infection site, and this process benefits parasite propagation in the host [39]. Results from studies in rats have shown that the rat NLRP1 sequence controls the macrophage sensitivity to pyroptosis in $T$. gondii infection and that the NLRP1 inflammasome correlates with macrophage cell death, parasite proliferation and IL-1 $\beta$ and IL-18 release $[18,40,41]$, while pyroptosis does not occur in $T$. gondii-infected mouse BMDMs [19, 41]. In our study, LDH-related cell death is correlated with the MOI of $N$. caninum, while the confirmation of pyroptosis in $N$. caninum-infected PMs should be done by macrophages from Caspase-1/11- and Gsdmd-deficient mice because recent studies have found that GSDMD, an inflammatory caspase substrate, is the direct and final executor of pyroptosis. When cleaved by active caspase-1, the N-terminal fragment of GSDMD rapidly targets the membrane fraction of macrophages and induces the formation of plasma membrane pores, causing cell lysis $[16,17,42]$. In addition, $N$. caninum ESAs can trigger mild IL-1 $\beta$ release, and this release is independent of the concentration of ESAs, indicating its essential role in triggering the host response to $N$. caninum infection [39], but $N$. caninum ESAs failed to induce cell death (data not show). Therefore, live $N$. caninum played a dominant role in inflammasome activation.

The sensor NLRP3 was the most upregulated molecule, and we hypothesized that NLRP3 played a predominant role in sensing $N$. caninum infection. We observed the recruitment of NLRP3 into the perinuclear space and the formation of puncta, indicating the activation of NLRP3 inflammasome. And N. caninum infection in $\mathrm{Nlrp3}^{-/-}$PMs displayed greatly decreased IL-1 $\beta$ release and inhibited caspase-1 cleavage, this result revealed and confirmed that inflammasome-mediated secretion of IL-1 $\beta$ and cleavage of caspase- 1 caused by $N$. caninum infection was highly dependent on NLRP3 inflammasome. The NLRP3 inflammasome is a critical component of innate immunity, which is thought to sense the disturbance of cellular homeostasis rather than directly recognize stimuli. Recently, the activation of the NLRP3 inflammasome in response to diverse stimuli has been proposed to be triggered by multiple cellular signals: $\mathrm{K}^{+}$efflux, $\mathrm{Ca}^{2+}$ signaling, mitochondrial dysfunction, and lysosomal rupture [14, 43-45]. For example, extracellular ATP triggers the NLRP3 inflammasome through the cell surface receptor P2X7R and $\mathrm{K}^{+}$efflux $[14,44]$. The mechanism of NLRP3 inflammasome activation caused by $N$. caninum infection requires further study.

The inflammasome plays essential roles in restricting parasite replication. Caspase-1/ASC inflammasome components played a significant role in the control of Trypanosoma cruzi replication, but NLRP3 was shown to be dispensable in parasite survival [46]. NLRP3 inflammasome activation contributed to the restriction of Leishmania spp. replication in both in vitro and in vivo experiments [47]. Toxoplasma gondii infection in NLRP1-, NLRP3- and caspase-1/11-deficient mice showed that NLRP1, NLRP3 and caspase-1/11 were essential for the restriction of parasite loads and survival of mice [19]. In our study, when pre-treated with inhibitors, $N$. caninum-infected PMs showed an impaired induction of IL-1 $\beta$ and failed to restrict parasite replication. In addition, $N$. caninum infection in $\mathrm{Nlrp}^{-/-} \mathrm{PMs}$ displayed extremely decreased release of IL- $1 \beta$ and inhibited cleavage of caspase-1. These data confirmed that the IL- $1 \beta$ release and caspase- 1 cleavage were mediated by inflammasome activity in $N$. caninum-infected PMs, especially highly dependent on NLRP3 inflammasome. We speculate that the activation of the inflammasome plays an important role in controlling $N$. caninum infection. Future studies are required to determine the mechanism of inflammasome activation by $N$. caninum infection in inflammasome-deficient mice in vivo. In addition, it is intriguing that IL- $1 \beta$ secretion could be only partially decreased by a caspase- 1 inhibitor, indicating that other caspases such as caspase-11 may participate in the inflammasome response to $N$. caninum infection, and further work will focus on this aspect.

\section{Conclusions}

We first demonstrated that the NLRP3 inflammasome in macrophages can be activated by $N$. caninum infection and mediates caspase- 1 processing and IL- $1 \beta$ release. In addition, the inflammasome plays an essential role in controlling $N$. caninum replication and survival in macrophages.

\section{Additional file}

Additional file 1: Figure S1. Effect of inhibitors on N. caninum replication in Vero cells. To evaluate whether the inhibitors used in this study could influence $N$. caninum replication, the inhibitors ZVAD-fmk (z), Ac-YVAD-CHO (y) and glyburide (g) were added to Vero cells for $45 \mathrm{~min}$, and the Vero cells were then infected with $N$. caninum tachyzoites $(\mathrm{MOI}=3: 1$; parasite:cell) for $12 \mathrm{~h}$. Total DNA from the infected cells was extracted and was used for a quantitative analysis by GPCR described in this study. The results showed that only glyburide could slightly inhibit $N$. caninum 
replication $(P=0.0393)$, while ZVAD-fmk and Ac-YVAD-CHO could not influence parasite replication compared with the Nc group. Meanwhile, parasitophorous vacuoles can be observed in each group (data not shown), indicating that these inhibitors did not influence the viability of $\mathrm{N}$. caninum. $\left({ }^{*} P<0.05 ;{ }^{* *} P<0.01 ;{ }^{* *} P<0.001\right.$ vs the Nc group). (TIF $\left.4400 \mathrm{~kb}\right)$

\section{Abbreviations}

ATP: Adenosine triphosphate; BSA: Bovine serum albumin; Ct: Threshold cycle; DAPI: 4',6-diamidino-2-phenylindole; DMSO: Dimethyl sulfoxide; ESAs: Excretory secretory antigens; FBS: Fetal bovine serum; LDH: Lactate dehydrogenase; LPS: Lipopolysaccharide; MOI: Multiplicities of infection; NLRs: Nucleotide oligomerization domain (Nod)-like receptors;

PBS: Phosphate buffer saline; PBST: Phosphate buffer saline with tween-20; PCR: Polymerase chain reaction; PMs: Peritoneal macrophages; qPCR: Quantitative polymerase chain reaction; SD: Standard deviation; TRITC: Tetramethylrhodamine isothiocyanate

\section{Funding}

Project support was provided by the "National Key Basic Research Program (973 program) of China" (Grant No. 2015CB150300) and the Special Fund for Scientific Research of Quality Inspection in the Public Interest in China (No. 201410061).

\section{Availability of data and materials}

The datasets supporting the conclusions of this article are included within the article and the additional file.

\section{Authors' contributions}

XW and PG designed this experimental work, and were involved in the work processing and preparing the manuscript. XZ participated in Western blot analysis and ELISA. JW assisted with the work involving confocal microscopy and immunofluorescence. LT and XW participated in the work of real-time PCR. ZW participated in data analysis. YY participated in the work of stimulation experiments. ZY assisted with the experimental design of stimulation experiments. $J L$ participated in data analysis and preparing manuscript. XZ participated in the design of the experimental work and helped to draft the manuscript. All authors read and approved the final manuscript.

\section{Competing interests}

The authors declare that they have no financial or other competing interests.

\section{Ethics approval and consent to participate}

Mice were maintained under standard conditions in the animal house of the Laboratory Animal Center of Jilin University. All experiments involving animals were approved by the Animal Care Committee in Jilin University (Changchun, China).

\section{Publisher's Note}

Springer Nature remains neutral with regard to jurisdictional claims in published maps and institutional affiliations.

\section{Received: 29 July 2016 Accepted: 15 May 2017}

\section{Published online: 30 May 2017}

\section{References}

1. Dubey JP, Schares G, Ortega-Mora LM. Epidemiology and control of neosporosis and Neospora caninum. Clin Microb Rev. 2007;20(2):323-67.

2. Dubey JP. Recent advances in Neospora and neosporosis. Vet Parasitol. 1999;84(3-4):349-67.

3. Innes EA. The host-parasite relationship in pregnant cattle infected with Neospora caninum. Parasitology. 2007;134(Pt 13):1903-10.

4. Reichel MP, Alejandra Ayanegui-Alcérreca M, Gondim LF, Ellis JT. What is the global economic impact of Neospora caninum in cattle - the billion dollar question. Intl J Parasitol. 2013;43(2):133-42.

5. Beiting DP, Peixoto L, Akopyants NS, Beverley SM, Wherry EJ, Christian DA, et al. Differential induction of TLR3-dependent innate immune signaling by closely related parasite species. PLoS One. 2014;9(2):e88398.

6. Reid AJ, Vermont SJ, Cotton JA, Harris D, Hill-Cawthorne GA, KönenWaisman $\mathrm{S}$, et al. Comparative genomics of the apicomplexan parasites
Toxoplasma gondii and Neospora caninum: Coccidia differing in host range and transmission strategy. PLoS Pathog. 2012;8(3):e1002567.

7. Davoli-Ferreira M, Fonseca DM, Mota CM, Dias MS, Lima-Junior DS, da Silva MV, et al. Nucleotide-binding oligomerization domain-containing protein 2 prompts potent inflammatory stimuli during Neospora caninum infection. Sci Rep. 2016;6:29289.

8. Franchi L, Warner N, Viani K, Nuñez G. Function of Nod-like receptors in microbial recognition and host defense. Immunol Rev. 2009;227(1):106-28.

9. Mineo TW, Oliveira CJ, Gutierrez FR, Silva JS. Recognition by Toll-like receptor 2 induces antigen-presenting cell activation and Th1 programming during infection by Neospora caninum. Immunol Cell Biol. 2010;88(8):825-33.

10. Zamboni DS, Lima-Junior DS. Inflammasomes in host response to protozoan parasites. Immunol Rev. 2015;265(1):156-71.

11. Franchi L, Muñoz-Planillo R, Núñez G. Sensing and reacting to microbes through the inflammasomes. Nat Immunol. 2012;13(4):325-32.

12. Newton $\mathrm{K}$, Dixit VM. Signaling in innate immunity and inflammation. Cold Spring Harb Perspect Biol. 2012;4(3):a006049.

13. Rathinam VA, Vanaja SK, Fitzgerald KA. Regulation of inflammasome signaling. Nat Immunol. 2012;13(4):333-42.

14. Horng T. Calcium signaling and mitochondrial destabilization in the triggering of the NLRP3 inflammasome. Trends Immunol. 2014;35(6):253-61.

15. Shi J, Zhao $Y$, Wang $K$, Shi $X$, Wang $Y$, Huang $H$, et al. Cleavage of GSDMD by inflammatory caspases determines pyroptotic cell death. Nature. 2015; 526(7575):660-5.

16. Chen $X$, He WT, Hu L, Li J, Fang Y, Wang X, et al. Pyroptosis is driven by non-selective gasdermin-D pore and its morphology is different from MLKL channel-mediated necroptosis. Cell Res. 2016;26(9):1007-20.

17. Ding J, Wang K, Liu W, She Y, Sun Q, Shi J, et al. Pore-forming activity and structural autoinhibition of the gasdermin family. Nature. 2016;535(7610): $111-6$.

18. Cirelli KM, Gorfu G, Hassan MA, Printz M, Crown D, Leppla SH, et al. Inflammasome sensor NLRP1 controls rat macrophage susceptibility to Toxoplasma gondii. PLoS Pathog. 2014;10(3):e1003927.

19. Gorfu G, Cirelli KM, Melo MB, Mayer-Barber K, Crown D, Koller BH, et al. Dual role for inflammasome sensors NLRP1 and NLRP3 in murine resistance to Toxoplasma gondii. MBio. 2014;5(1):e01117-13.

20. Abe C, Tanaka S, Nishimura M, Ihara F, Xuan X, Nishikawa Y. Role of the chemokine receptor CCR5-dependent host defense system in Neospora caninum infections. Parasit Vectors. 2015;8:5.

21. Saadatnia G, Mohamed Z, Ghaffarifar F, Osman E, Moghadam ZK, Noordin R. Toxoplasma gondii excretory secretory antigenic proteins of diagnostic potential. APMIS. 2012;120(1):47-55.

22. Malvezi AD, da Silva RV, Panis C, Yamauchi LM, Lovo-Martins MI, Zanluqui $N G$, et al. Aspirin modulates innate inflammatory response and inhibits the entry of Trypanosoma cruzi in mouse peritoneal macrophages. Mediators Inflamm. 2014;2014:580919.

23. Lech M, Avila-Ferrufino A, Skuginna V, Susanti HE, Anders HJ. Quantitative expression of RIG-like helicase, NOD-like receptor and inflammasomerelated mRNAs in humans and mice. Int Immunol. 2010;22(9):717-28.

24. Yu SX, Du CT, Chen W, Lei QQ, Li N, Qi S, et al. Genipin inhibits NLRP3 and NLRC4 inflammasome activation via autophagy suppression. Sci Rep. 2015;5: 17935.

25. Collantes-Fernández E, Zaballos A, Alvarez-García G, Ortega-Mora LM. Quantitative detection of Neospora caninum in bovine aborted fetuses and experimentally infected mice by real-time PCR. J Clin Microbiol. 2002;40(4): $1194-8$.

26. Mortimer L, Moreau F, Cornick S, Chadee K. The NLRP3 Inflammasome Is a Pathogen Sensor for Invasive Entamoeba histolytica via Activation of alpha5beta1 Integrin at the Macrophage-Amebae Intercellular Junction. PLoS Pathog. 2015;11(5):e1004887.

27. Yang J, Liu Z, Xiao TS. Post-translational regulation of inflammasomes. Cell Mol Immunol. 2017;14(1):65-79.

28. Abe C, Tanaka S, Ihara F, Nishikawa Y. Macrophage depletion prior to Neospora caninum infection results in severe neosporosis in mice. Clin Vaccine Immunol. 2014;21 (8):1185-8.

29. Khan IA, Schwartzman JD, Fonseka S, Kasper LH. Neospora caninum: role for immune cytokines in host immunity. Exp Parasitol. 1997;85(1):24-34.

30. Nishikawa Y, Tragoolpua K, Inoue N, Makala L, Nagasawa H, Otsuka H, Mikami T. In the absence of endogenous gamma interferon, mice acutely infected with Neospora caninum succumb to a lethal immune response 
characterized by inactivation of peritoneal macrophages. Clin Diagn Lab Immunol. 2001;8(4):811-6.

31. Correia A, Ferreirinha P, Botelho S, Belinha A, Leitão C, Caramalho I, et al. Predominant role of interferon-gamma in the host protective effect of CD8(+) T cells against Neospora caninum infection. Sci Rep. 2015;5:14913.

32. Teixeira L, Marques RM, Ferreirinha P, Bezerra F, Melo J, Moreira J, et al. Enrichment of IFN-gamma producing cells in different murine adipose tissue depots upon infection with an apicomplexan parasite. Sci Rep. 2016;6:23475.

33. Jesus EE, Pinheiro AM, Santos AB, Freire SM, Tardy MB, El-Bachá RS, et al. Effects of IFN-gamma, TNF-alpha, IL-10 and TGF-beta on Neospora caninum infection in rat glial cells. Exp Parasitol. 2013;133(3):269-74.

34. Almeria S, Serrano B, Yàniz JL, Darwich L, López-Gatius F. Cytokine gene expression profiles in peripheral blood mononuclear cells from Neospora caninum naturally infected dams throughout gestation. Vet Parasitol. 2012;183(3-4):237-43.

35. Chow MT, Duret H, Andrews DM, Faveeuw C, Möller A, Smyth MJ, Paget C. Type I NKT-cell-mediated TNF-alpha is a positive regulator of NLRP3 inflammasome priming. Eur J Immunol. 2014;44(7):2111-20.

36. Franchi L, Eigenbrod T, Núñez G. Cutting edge. TNF-alpha mediates sensitization to ATP and silica via the NLRP3 inflammasome in the absence of microbial stimulation. J Immunol. 2009:183(2):792-6.

37. Chavarría-Smith J, Vance RE. Direct proteolytic cleavage of NLRP1B is necessary and sufficient for inflammasome activation by anthrax lethal factor. PLoS Pathog. 2013;9(6):e1003452.

38. Lamkanfi M, Dixit VM. Manipulation of host cell death pathways during microbial infections. Cell Host Microbe. 2010;8(1):44-54.

39. Mineo TW, Oliveira CJ, Silva DA, Oliveira LL, Abatepaulo AR, Ribeiro DP, et al. Neospora caninum excreted/secreted antigens trigger CC-chemokine receptor 5-dependent cell migration. Int J Parasitol. 2010:40(7):797-805.

40. Cavailles P, Flori P, Papapietro O, Bisanz C, Lagrange D, Pilloux L, et al. A highly conserved Toxo1 haplotype directs resistance to toxoplasmosis and its associated caspase-1 dependent killing of parasite and host macrophage. PLoS Pathog. 2014;10(4):e1004005.

41. Ewald SE, Chavarria-Smith J, Boothroyd JC. NLRP1 is an inflammasome sensor for Toxoplasma gondii. Infect Immun. 2014;82(1):460-8.

42. Sborgi L, Rühl S, Mulvihill E, Pipercevic J, Heilig R, Stahlberg H, et al. GSDMD membrane pore formation constitutes the mechanism of pyroptotic cell death. EMBO J. 2016;35(16):1766-78.

43. He Y, Hara H, Núñez G. Mechanism and regulation of NLRP3 inflammasome activation. Trends Biochem Sci. 2016;41(12):1012-21.

44. Elliott El, Sutterwala FS. Initiation and perpetuation of NLRP3 inflammasome activation and assembly. Immunol Rev. 2015;265(1):35-52.

45. Lamkanfi M, Dixit VM. Inflammasomes and their roles in health and disease. Annu Rev Cell Dev Biol. 2012;28:137-61.

46. Dey N, Sinha M, Gupta S, Gonzalez MN, Fang R, Endsley JJ, et al. Caspase-1/ ASC inflammasome-mediated activation of IL-1 beta-ROS-NF-kappaB pathway for control of Trypanosoma cruzi replication and survival is dispensable in NLRP3-/- macrophages. PLoS One. 2014;9(11):e111539.

47. Lima-Junior DS, Costa DL, Carregaro V, Cunha LD, Silva AL, Mineo TW, et al. Inflammasome-derived IL-1 beta production induces nitric oxide-mediated resistance to Leishmania. Nat Med. 2013;19(7):909-15.

\section{Submit your next manuscript to BioMed Central and we will help you at every step:}

- We accept pre-submission inquiries

- Our selector tool helps you to find the most relevant journal

- We provide round the clock customer support

- Convenient online submission

- Thorough peer review

- Inclusion in PubMed and all major indexing services

- Maximum visibility for your research

Submit your manuscript at www.biomedcentral.com/submit

) Biomed Central 